\title{
Cervical Total Disc Replacement and Heterotopic Ossification: A Review of Literature Outcomes and Biomechanics
}

\author{
Nicholas Hui ${ }^{1,2}$, Kevin Phan ${ }^{1,2}$, Jack Kerferd ${ }^{1,2}$, Meiyi Lee ${ }^{1,3}$, Ralph Jasper Mobbs ${ }^{1,2,4}$ \\ ${ }^{1}$ NeuroSpine Surgery Research Group, Sydney, Australia \\ ${ }^{2}$ Faculty of Medicine, University of New South Wales, Sydney, Australia \\ ${ }^{3}$ Faculty of Health and Social Sciences, The Hong Kong Polytechnic University, Hong Kong \\ ${ }^{4}$ NeuroSpineClinic, Sydney, Australia
}

\begin{abstract}
Anterior cervical discectomy and fusion (ACDF) immobilizes surgical segments and can lead to the development of adjacent segment degeneration and adjacent segment disease. Thus, cervical total disc replacement (CTDR) has been developed with the aim to preserve the biomechanics of spine. However, heterotopic ossification (HO), a complication following CTDR, can reduce the segmental range of motion (ROM) and defects the motion-preservation benefit of CTDR. The pathological process of HO in CTDR remains unknown. $\mathrm{HO}$ has been suggested to be a self-defense mechanism in response to the non-physiological biomechanics of the cervical spine following CTDR. The current literature review is concerned with the association between the biomechanical factors and HO formation and the clinical significance of $\mathrm{HO}$ in CTDR. Endplate coverage, disc height, segmental angle, and center of rotation may be associated with the development of HO. The longer the follow-up, the higher the rate of ROM-limiting HO. Regardless of the loss of motion-preservation benefit of CTDR in patients with HO, CTDR confers patients with a motion-preservation period before the development of ROM-limiting HO. This may delay the development of adjacent segment degeneration compared with ACDF. Future clinical studies should explore the association between $\mathrm{HO}$ and changes in biomechanical factors of the cervical spine.
\end{abstract}

Keywords: Ossification; Heterotopic; Total disc replacement; Spine; Biomechanical phenomena

\section{Introduction}

Cervical total disc replacement (CTDR) has emerged as an alternative to anterior cervical discectomy and fusion (ACDF). In theory, the major advantage of CTDR over $\mathrm{ACDF}$ is the preservation of segmental range of motion (ROM) and function, thereby minimizing the risk of adjacent segment degeneration (ASD) [1]. ROM preservation can alleviate intradiscal pressure and stress at levels adja- cent to the operated segments [2]. Compared with ACDF, CTDR demonstrates superiority in some aspects of clinical outcome, such as a higher rate of neurological success, while maintaining non-inferiority in the majority of other clinical and safety outcomes [3]. Unfortunately, heterotopic ossification (HO), which is consistently reported as a complication in clinical trials, may impact the long-term superiority of CTDR over ACDF.

The pathological process underlying the development

Received Jul 24, 2019; Revised Aug 28, 2019; Accepted Sep 11, 2019

Corresponding author: Ralph Jasper Mobbs

NeuroSpineClinic, Suite 7, Level 7, Prince of Wales Private Hospital, Randwick, New South Wales 2031, Australia

Tel: +61-0296504766, Fax: +61-0296504902, E-mail: ralphmobbs@hotmail.com 
of $\mathrm{HO}$ remains unclear. Although a number of modifiable and non-modifiable risk factors have been found to be associated with $\mathrm{HO}$ formation, the evidence is inconclusive [4,5]. Additionally, the postoperative use of non-steroidal anti-inflammatory drugs does not seem effective in reducing the rate of $\mathrm{HO}$ [6]. Three conditions have been postulated as essential for $\mathrm{HO}$ formation-osteogenic precursor cells, inducing agents, and a permissive environment [7]. The current literature review has the following objectives: (1) to discuss what biomechanical factors may act as an inducing agent of and create a permissive environment for $\mathrm{HO}$ formation in CTDR and (2) to discuss the clinical significance of $\mathrm{HO}$.

\section{Materials and Methods}

A systematic review on the association between biomechanical factors of the cervical spine and HO in CTDR was conducted in accordance with the Preferred Reporting Items for Systematic Review and Meta-Analysis protocols guideline and the guidelines for academic neurosurgeons [8-10]. We searched in the MEDLINE, EMBASE, Cochrane Central Register of Controlled Trials, and PubMed databases for eligible studies published until April 2018. The following medical subject headings and text words were used: "heterotopic ossification," "het- erotopic bone," "cervical," "arthroplasty," "total disc/disk replacement," "artificial disc/disk replacement," and "disc/ disk prosthesis." A search in the reference lists of all the selected articles was manually performed to identify other potential studies.

After removal of duplicates and screening of title and abstract, full-text eligible studies were reviewed. The whole screening and reviewing process was conducted by two reviewers. Any disagreement in the reviewing process was first resolved by a discussion between the reviewers. If the reviewers could not reach a consensus, a senior author was consulted.

The inclusion criteria were as follows: (1) studies that reported the association between $\mathrm{HO}$ and $\geq 1$ biomechanical factor(s); (2) subjects aged $\geq 18$ years; and (3) there is no limitation on the number of doctors who diagnosed $\mathrm{HO}$, the type of prosthesis, or the classification system used to grade HO. The exclusion criteria were as follows: (1) articles that did not provide original data, such as editorials; (2) studies written in languages other than English; (3) TDR in the lumbar spine; and (4) duplicated publications.

\section{Biomechanical Factors}

The human spine is a biomechanically complex structure.
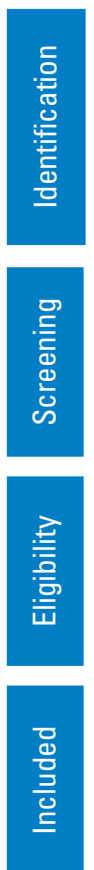

\section{Records identified through database searching}

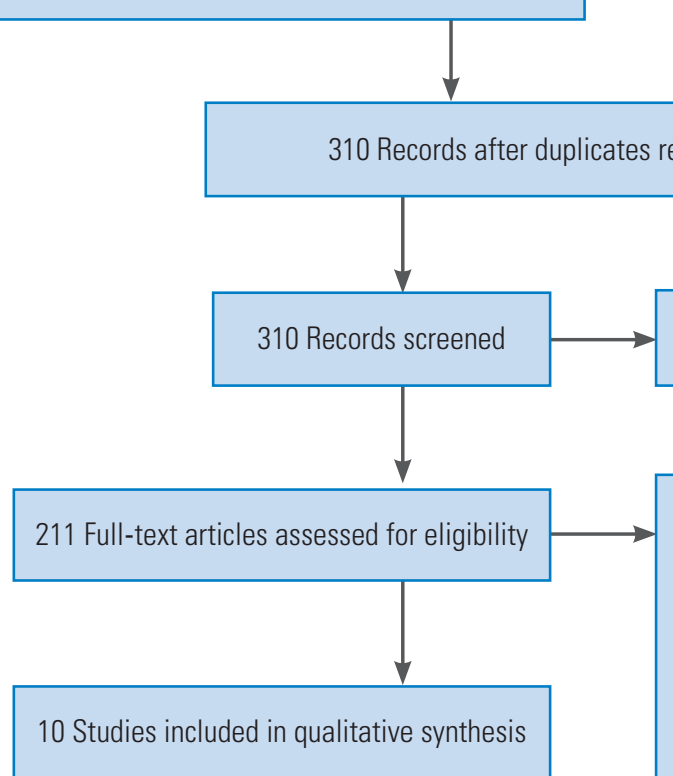

30 Additional records identified through other sources

99 Records excluded after screening of titles and abstracts

201 Full-text articles excluded, with reasons

- 132 No data on the association between biomechanical factor and $\mathrm{HO}$

- 20 Foreign language

- 4 Letter/commentary

- 32 Review articles

- 13 Used same set of patients

Fig. 1. PRISMA flow diagram. HO, heterotopic ossification; PRISMA, Preferred Reporting Items for Systematic Review and Meta-Analysis. 
The replacement of cervical intervertebral discs with artificial implants designed to mimic natural motion is done in an attempt to preserve segmental- and adjacent-level motion [11]. However, there is potential for these devices to still result in non-physiological strain [12]. Cho et al. $[13,14]$ reasoned that $\mathrm{HO}$ could actually be a self-defense mechanism in response to the non-physiological biomechanics of the cervical spine following CTDR. In order to investigate the association between biomechanical factors and $\mathrm{HO}$, our initial search produced 310 articles after removal of duplicates, of which 10 studies were included in our review (Fig. 1) [5,12,15-22].

\section{Endplate Coverage}

Inappropriate endplate coverage may be associated with the development of HO. Pickett et al. [23] first proposed that the formation of grade IV $\mathrm{HO}$ at 17-month followup in a patient was due to undersizing of the prosthesis. This theory is corroborated in a retrospective study of the Bryan cervical disc, which classified "suboptimal carpentry group" as an uncovered vertebral endplate of $>1 \mathrm{~mm}$ and/or kyphotic position of the implant [12]. They discovered that the suboptimal carpentry group was associated with a higher rate of grade II or more severe $\mathrm{HO}$ at 2-year follow-up [12]. In fact, the footprint mismatch between the endplates and prostheses was $43.7 \%$ in the Bryan and ProDisc-C, 60.4\% in Discover, and 100\% in Prestige implants in the anterior-posterior plane [24]. However, results are not unanimous, with vertebral endplate coverage not being significantly associated with a higher rate of ROM-limiting HO in patients undergoing CTDR with the ProDisc-C implant [16]. The use of different types of implant may explain the contradictory results in the studies. Additionally, Wenger et al. [25] postulated that complete endplate coverage could block osseous outgrowth of endplate, and, thus, minimize the risk of HO. As such, it has been recommended that CTDR prosthetics should be as large as possible to cover the whole endplate, dissipating loading force evenly across the endplate [24].

\section{Disc Height}

Disc height could potentially be another biomechanical factor contributing to $\mathrm{HO}$ formation. Although an increase in disc height is necessary in order to properly decompress the nerve roots, over-distraction of disc height is correlated with increased segmental ROM [16]. This result is in agreement with another study which found that approximately $30 \%$ of the inter-subject variability in $\mathrm{C} 5 /$ C6 and C6/C7 flexion-extension ROM could be attributed to the differences in disc height at these segments [26]. Given the changes in disc height and ROM after CTDR, $\mathrm{HO}$ has been theorized to stabilize the non-physiological movement of cervical spine $[13,14]$. However, the association between $\mathrm{HO}$ and disc height is yet to be proven.

\section{Segmental Angle}

Segmental angle is altered after CTDR with some types of prosthesis. Following CTDR using Bryan disc prosthesis, segmental angle became kyphotic relative to the preoperative segmental angle [27]. A prospective study quantified that only $36 \%$ of patients with segmental lordosis before CTDR had segmental lordosis preserved postoperation [28]. In spite of the loss of segmental lordosis in some subjects, the C2/C7 Cobb angle did not change significantly; as such, other cervical levels might have compensated for the loss of physiological alignment at surgical segment $[27,29]$. In contrast to the Bryan disc, ProDisc-C has been reported to result in significantly more lordosis at the surgical segment and across the global cervical spine [30,31].

The angle of the surgical spinal segment is associated with its ROM. An in vivo study demonstrated an inverse association between shell angle with segmental ROM in flexion and extension [32]. Also, an increase in flexionextension ROM after CTDR with ProDisc-C prosthesis has been reported in both in vitro and in vivo studies $[33,34]$. Theoretically, increased segmental mobility can accentuate strain on the uncovertebral and facet joints [35]. Hence, Rabin et al. [32] recommended that upper and lower device endplates should be parallel to each other when inserted into the disc space to preserve segmental ROM. Although HO may develop in response to the nonphysiological biomechanics of the cervical spine following CTDR $[13,14]$, the effect of segmental hypermobility on $\mathrm{HO}$ development is unproven.

\section{Center of Rotation}

Center of rotation (COR) of the cervical spine is altered after CTDR. By adopting a finite element model of the C5/C6 cervical spine after CTDR, a biomechanical study found that the position of instantaneous COR of Bryan 


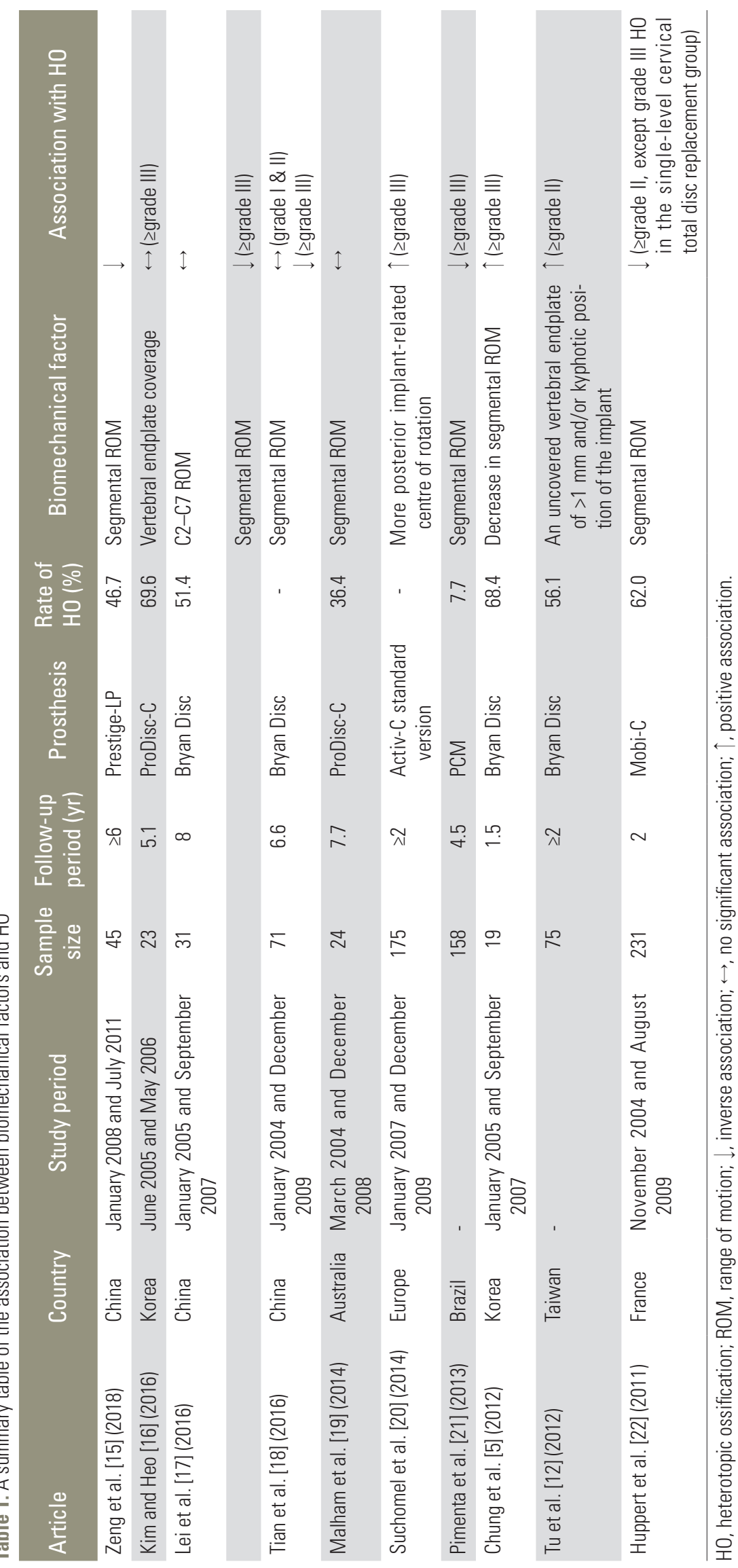


disc was less stable than that in intact cervical spine during flexion-extension movement [36]. Another radiological study examining Prestige LP and ProDisc-C prostheses showed that COR-Y (directed perpendicular to the endplate) was significantly different from the healthy controls while COR-X (directed along the $\mathrm{X}$-axis of superior endplate of the lower vertebral body) was significantly more anterior to the control group [37]. Significant changes in postoperative COR-X and COR-Y have been reported in another study examining ProDisc-C and Synergy prostheses [35]. Indeed, a more posterior COR was correlated with a higher rate of $\mathrm{HO}$ [20]. Tu et al. [2] suggested that surgeons should place implants at the center of the disc space, with symmetrical disc space from the sides. However, such suggestion did not take the physiological $\mathrm{COR}$ in human spine into consideration. In general, finite axis of rotation is situated inferior to the intervertebral disc and posterior to the center of the endplate $[38,39]$. Moreover, from $\mathrm{C} 1$ to $\mathrm{C} 7$, axis of rotation gradually moves more superiorly and anteriorly $[38,39]$. Thus, COR of each cervical level is different from that of the other cervical levels.

To summarize, evidence on whether CTDR can restore cervical kinematics back to normal is lacking. While CTDR with Prestige prosthesis was found more compatible to physiological kinematics of spine than the Bryan disc, both types of prosthesis simulated significantly different spinal kinematics from the healthy population [40]. Incompatibility of spinal kinematics after CTDR with physiological kinematics may, therefore, be an inducing agent of HO [41]. Notably, some biomechanical factors are associated with the development of HO in CTDR (Table 1).

\section{Does Heterotopic Ossification Really Matter to Patients in Cervical Total Disc Replacement?}

Evidence about the association between follow-up period and $\mathrm{HO}$ is conflicting. A retrospective study with an average of 36.9-month follow-up period showed that over time patients were more likely to develop new and more severe HO [42]. Strikingly, in a meta-analysis of 38 studies, the prevalence of $\mathrm{HO}$ was comparable among studies with 1-2-year, 2-5-year, and 5-10-year follow-up [43]. Also, there was no significant association between $\mathrm{HO}$ and the duration of follow-up. The conflicting results can

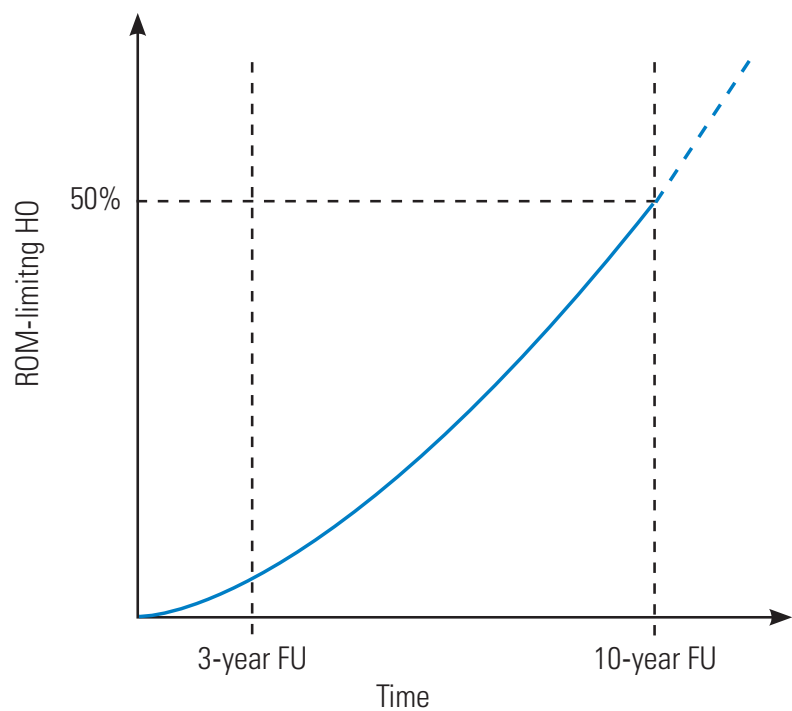

Fig. 2. The association between the rate of ROM-limiting $\mathrm{HO}$ and the duration of FU after CTDR. ROM, range of motion; HO, heterotopic ossification; CTDR, cervical total disc replacement; FU, follow-up.

be attributed to the inclusion of studies with long followup period in the meta-analysis.

In contrast to overall $\mathrm{HO}$, the rate of ROM-limiting $\mathrm{HO}$ seemed to correlate with time [43]. A meta-analysis showed that the rates of ROM-limiting HO in studies with 2-5-year and 5-10-year follow-up were higher than those of studies with 1-2-year follow-up [43]. The positive association between ROM-limiting $\mathrm{HO}$ and follow-up duration is further supported by our meta-analysis of 94 clinical trials on CTDR [44]. There was $0.63 \%$ increase of ROM-limiting $\mathrm{HO}$ for every increase of one month in the follow-up time [43]. Given long enough follow-up time after CTDR, all prosthesis may eventually develop ROMlimiting $\mathrm{HO}$ (Fig. 2). However, patients are unlikely to develop ROM-limiting HO shortly after CTDR. In studies with an average or mean follow-up shorter than 3 years, most reported no cases of ROM-limiting HO [28,45-62]. The median HO-free period was 27.1 months [63].

Although CTDR was designed to preserve segmental ROM and prevent the development of ASD, deviation of postoperative ROM from the preoperative values has been reported in clinical trials. Segmental ROM has been reported to decrease shortly after surgery and could persist up to 6-month follow-up in some studies [30,58,64-67]. Factors that might have led to the decrease in segmental ROM reported in the studies include the following: (1) the cohort of subjects has greater impairment in ROM preoperatively [68]; (2) fear of moving the neck to the extremes 


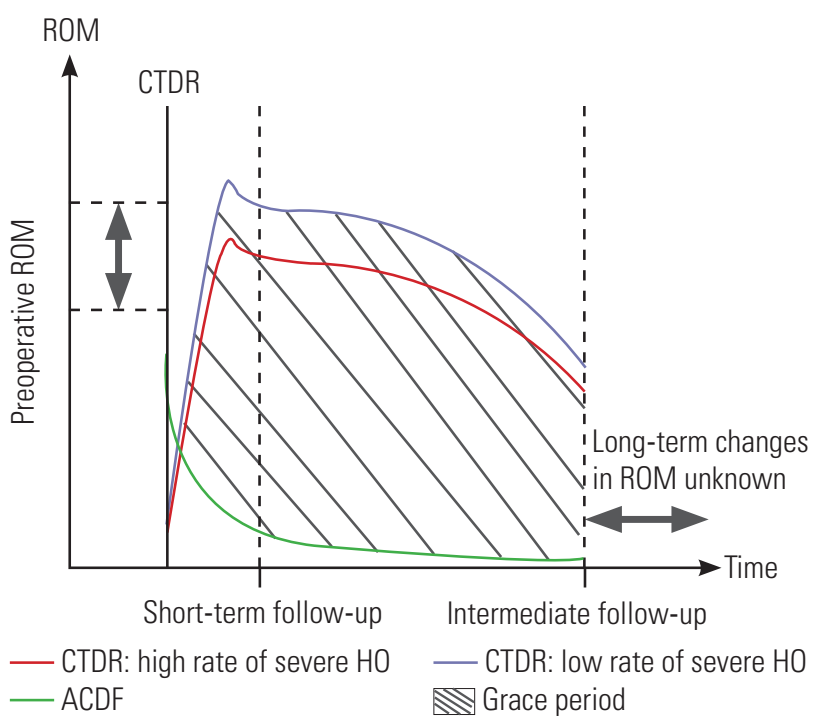

Fig. 3. Grace period of $\mathrm{HO}$ formation. ROM of the operated segment may be unchanged or more mobile in comparison with preoperative ROM in short-term follow-up. ROM tends to decrease as follow-up time increases. There is a "grace period" where operated segment remains mobile before $\mathrm{ROM}$-limiting $\mathrm{HO}$ forms. $\mathrm{HO}$, heterotopic ossification; ROM, range of motion; CTDR, cervical total disc replacement; ACDF, anterior cervical discectomy and fusion.

of flexion and extension during dynamic X-ray; (3) and postoperative neck pain [30]. However, in longer term follow-up, ROM became comparable to preoperative values [30,58,64-67]. Other studies have reported preserved segmental ROM compared with preoperative ROM at 1-2year [14,20,55,69-72], 3-5-year [73-80], 7-year [81], and 8 -year follow-up [82]. Interestingly, some studies even reported significantly more mobile segments over 1-year follow-up [48] than at 5-year follow-up [83]. Of note, the rate of grade IV $\mathrm{HO}$ reported ranges from $0 \%$ to $2.9 \%$ in these studies $[48,83]$, which are lower than those reported in meta-analyses of CTDR [43,84]. Since grade IV HO is known to bridge across the disc space and significantly restricts the segmental ROM, the low prevalence of grade IV $\mathrm{HO}$ in these trials may explain the increased segmental ROM (Fig. 3).

On the contrary, in studies with intermediate or longterm follow-up, ROM tends to significantly decrease in relation to preoperative ROM. Segmental ROM significantly decreased at 2-year [52,68], 4-year [85], >6-year [15], average 8-year [17], and average 10-year follow-up [86]. As the severity of $\mathrm{HO}$ and the incidence of ROMlimiting $\mathrm{HO}$ correlated with the length of the follow-up period $[42,43]$, the formation of ROM-limiting HO may be accounted for the reduced ROM reported in clinical trials with intermediate to long-term follow-up. Indeed, the segmental ROM was reduced in patients with $\mathrm{HO}$ $[5,17,18]$ and those with grade II or higher $\mathrm{HO}$ [22]. The decrease in segmental ROM was significantly higher in patients who developed ROM-limiting HO, compared to patients with ROM-preserving $\mathrm{HO}$ and those without $\mathrm{HO}$ [5]. Also, $\mathrm{HO}$ formation was correlated with reduced ROM in a study with over 6-year follow-up [15], but not over 5-year follow-up [19]. Similarly, ROM-limiting HO was inversely associated with segmental ROM [21].

Overall, the segmental ROM shortly after CTDR is comparable or even higher than that before surgery. As shown in Fig. 3, segmental ROM tends to be preserved in short- to intermediate-term follow-up [14,20,30,55,58,6467,69-82], and the prosthesis continues to exercise its biomechanical functions. As the follow-up time increases, there will be an increased rate of ROM-limiting $\mathrm{HO}$, which is functionally similar, if not identical, to the fused segments in ACDF [43]. While HO is gradually fusing the spinal segments, the formation of ROM-limiting HO is preceded by years of preservation of segmental mobility $[14,20,30,55,58,64-67,69-82]$. The years of preserved segmental mobility may serve, in theory, as a "grace period" to delay the formation of ASD in CTDR, compared with ACDF (Fig. 3). Although a meta-analysis showed that the rate of adjacent segment disease is significantly lower in CTDR than ACDF at 2-year follow-up, intermediate- to long-term data are lacking [87]. In addition, HO formation does not seem to significantly jeopardize clinical outcomes of patients in short- to intermediate-term followup [88]. Therefore, CTDR may confer patients, at least, non-inferior clinical outcomes in short- to intermediateterm follow-up, in comparison with ACDF. Long-term data on the clinical and radiological outcomes are warranted to ascertain the safety profile of CTDR.

\section{Conclusions}

The biomechanical parameters of the operative segment and cervical spine are altered following CTDR. Some studies demonstrated that the changes in biomechanical factors were associated with the prevalence and/or severity of HO; however, a causal relationship between these factors remains unproven. Regardless, $\mathrm{HO}$ formation has not been shown to correlate with clinical outcomes in meta-analyses of short- to intermediate-term follow-up studies. CTDR preserves segmental mobility for years and 
confers patients a grace period to delay the formation of ASD, compared with ACDF. Clinical trials with long-term follow-up are warranted to confirm the extended efficacy of CTDR in light of increased rates of ROM-limiting HO.

\section{Conflict of Interest}

No potential conflict of interest relevant to this article was reported.

\section{Author Contributions}

All authors participated in the conception of the manuscript. N.H. led the drafting under the supervision of K.P. and R.J.M. All authors revised the manuscript critically for important intellectual content.

\section{References}

1. Heller JG, Sasso RC, Papadopoulos SM, et al. Comparison of BRYAN cervical disc arthroplasty with anterior cervical decompression and fusion: clinical and radiographic results of a randomized, controlled, clinical trial. Spine (Phila Pa 1976) 2009;34:101-7.

2. Tu TH, Wu JC, Huang WC, et al. Heterotopic ossification after cervical total disc replacement: determination by CT and effects on clinical outcomes. J Neurosurg Spine 2011;14:457-65.

3. Gao Y, Liu M, Li T, Huang F, Tang T, Xiang Z. A meta-analysis comparing the results of cervical disc arthroplasty with anterior cervical discectomy and fusion (ACDF) for the treatment of symptomatic cervical disc disease. J Bone Joint Surg Am 2013;95:55561.

4. Yi S, Shin DA, Kim KN, et al. The predisposing factors for the heterotopic ossification after cervical artificial disc replacement. Spine J 2013;13:1048-54.

5. Chung SB, Muradov JM, Lee SH, Eoh W, Kim ES. Uncovertebral hypertrophy is a significant risk factor for the occurrence of heterotopic ossification after cervical disc replacement: survivorship analysis of Bryan disc for single-level cervical arthroplasty. Acta Neurochir (Wien) 2012;154:1017-22.

6. Tu TH, Wu JC, Huang WC, et al. Postoperative nonsteroidal antiinflammatory drugs and the prevention of heterotopic ossification after cervical arthroplasty: analysis using CT and a minimum 2-year follow-up.
J Neurosurg Spine 2015;22:447-53.

7. Chalmers J, Gray DH, Rush J. Observations on the induction of bone in soft tissues. J Bone Joint Surg Br 1975;57:36-45.

8. Phan K, Tian DH, Cao C, Black D, Yan TD. Systematic review and meta-analysis: techniques and a guide for the academic surgeon. Ann Cardiothorac Surg 2015;4:112-22.

9. Phan K, Mobbs RJ. Systematic reviews and metaanalyses in spine surgery, neurosurgery and orthopedics: guidelines for the surgeon scientist. J Spine Surg 2015;1:19-27.

10. Moher D, Shamseer L, Clarke M, et al. Preferred reporting items for systematic review and metaanalysis protocols (PRISMA-P) 2015 statement. Syst Rev 2015;4:1.

11. Dmitriev AE, Cunningham BW, Hu N, Sell G, Vigna F, McAfee PC. Adjacent level intradiscal pressure and segmental kinematics following a cervical total disc arthroplasty: an in vitro human cadaveric model. Spine (Phila Pa 1976) 2005;30:1165-72.

12. Tu TH, Wu JC, Huang WC, Wu CL, Ko CC, Cheng $\mathrm{H}$. The effects of carpentry on heterotopic ossification and mobility in cervical arthroplasty: determination by computed tomography with a minimum 2-year follow-up: clinical article. J Neurosurg Spine 2012;16:601-9.

13. Cho YH, Kim KS, Kwon YM. Heterotopic ossification after cervical arthroplasty with ProDisc-C: time course radiographic follow-up over 3 years. Korean J Spine 2013;10:19-24.

14. Cho HJ, Shin MH, Huh JW, Ryu KS, Park CK. Heterotopic ossification following cervical total disc replacement: iatrogenic or constitutional? Korean J Spine 2012;9:209-14.

15. Zeng J, Liu H, Wang B, et al. Clinical and radiographic comparison of cervical disc arthroplasty with Prestige-LP Disc and anterior cervical fusion: a minimum 6-year follow-up study. Clin Neurol Neurosurg 2018;164:97-102.

16. Kim KS, Heo DH. Do postoperative biomechanical changes induce heterotopic ossification after cervical arthroplasty?: a 5-year follow-up study. Clin Spine Surg 2016;29:E309-13.

17. Lei T, Liu Y, Wang H, et al. Clinical and radiological analysis of Bryan cervical disc arthroplasty: eightyear follow-up results compared with anterior cervi- 
cal discectomy and fusion. Int Orthop 2016;40:1197203.

18. Tian W, Fan MX, Liu YJ, et al. An analysis of paravertebral ossification in cervical artificial disc replacement: a novel classification based on computed tomography. Orthop Surg 2016;8:440-6.

19. Malham GM, Parker RM, Ellis NJ, Chan PG, Varma D. Cervical artificial disc replacement with ProDiscC: clinical and radiographic outcomes with longterm follow-up. J Clin Neurosci 2014;21:949-53.

20. Suchomel P, Jurak L, Antinheimo J, et al. Does sagittal position of the CTDR-related centre of rotation influence functional outcome?: prospective 2-year follow-up analysis. Eur Spine J 2014;23:1124-34.

21. Pimenta L, Oliveira L, Coutinho E, Marchi L. Bone formation in cervical total disk replacement (CTDR) up to the 6-year follow-up: experience from $272 \mathrm{lev}$ els. Neurosurg Q 2013;23:1-6.

22. Huppert J, Beaurain J, Steib JP, et al. Comparison between single- and multi-level patients: clinical and radiological outcomes 2 years after cervical disc replacement. Eur Spine J 2011;20:1417-26.

23. Pickett GE, Sekhon LH, Sears WR, Duggal N. Complications with cervical arthroplasty. J Neurosurg Spine 2006;4:98-105.

24. Thaler M, Hartmann S, Gstottner M, Lechner R, Gabl M, Bach C. Footprint mismatch in total cervical disc arthroplasty. Eur Spine J 2013;22:759-65.

25. Wenger M, Hoonacker Pv, Zachee B, Lange R, Markwalder TM. Bryan cervical disc prostheses: preservation of function over time. J Clin Neurosci 2009;16:220-5.

26. Anderst WJ, Donaldson WF 3rd, Lee JY, Kang JD. Continuous cervical spine kinematics during in vivo dynamic flexion-extension. Spine J 2014;14:1221-7.

27. Pickett GE, Mitsis DK, Sekhon LH, Sears WR, Duggal N. Effects of a cervical disc prosthesis on segmental and cervical spine alignment. Neurosurg Focus 2004;17:E5.

28. Kim SW, Shin JH, Arbatin JJ, Park MS, Chung YK, McAfee PC. Effects of a cervical disc prosthesis on maintaining sagittal alignment of the functional spinal unit and overall sagittal balance of the cervical spine. Eur Spine J 2008;17:20-9.

29. Johnson JP, Lauryssen C, Cambron HO, et al. Sagittal alignment and the Bryan cervical artificial disc. Neurosurg Focus 2004;17:E14.
30. Ahn PG, Kim KN, Moon SW, Kim KS. Changes in cervical range of motion and sagittal alignment in early and late phases after total disc replacement: radiographic follow-up exceeding 2 years. J Neurosurg Spine 2009;11:688-95.

31. Anakwenze OA, Auerbach JD, Milby AH, Lonner BS, Balderston RA. Sagittal cervical alignment after cervical disc arthroplasty and anterior cervical discectomy and fusion: results of a prospective, randomized, controlled trial. Spine (Phila Pa 1976) 2009;34:20017.

32. Rabin D, Bertagnoli R, Wharton N, Pickett GE, Duggal N. Sagittal balance influences range of motion: an in vivo study with the ProDisc-C. Spine J 2009;9:12833.

33. DiAngelo DJ, Foley KT, Morrow BR, et al. In vitro biomechanics of cervical disc arthroplasty with the ProDisc-C total disc implant. Neurosurg Focus 2004;17:E7.

34. Bertagnoli R, Yue JJ, Pfeiffer F, et al. Early results after ProDisc-C cervical disc replacement. J Neurosurg Spine 2005;2:403-10.

35. Lazaro BC, Yucesoy K, Yuksel KZ, et al. Effect of arthroplasty design on cervical spine kinematics: analysis of the Bryan disc, ProDisc-C, and Synergy disc. Neurosurg Focus 2010;28:E6.

36. Galbusera F, Fantigrossi A, Raimondi MT, Sassi M, Fornari M, Assietti R. Biomechanics of the C5-C6 spinal unit before and after placement of a disc prosthesis. Biomech Model Mechanobiol 2006;5:253-61.

37. Rousseau MA, Cottin P, Levante S, Nogier A, Lazennec JY, Skalli W. In vivo kinematics of two types of ball-and-socket cervical disc replacements in the sagittal plane: cranial versus caudal geometric center. Spine (Phila Pa 1976) 2008;33:E6-9.

38. Dvorak J, Panjabi MM, Novotny JE, Antinnes JA. In vivo flexion/extension of the normal cervical spine. J Orthop Res 1991;9:828-34.

39. Galbusera F, Bellini CM, Brayda-Bruno M, Fornari M. Biomechanical studies on cervical total disc arthroplasty: a literature review. Clin Biomech (Bristol, Avon) 2008;23:1095-104.

40. Wachowski MM, Wagner M, Weiland J, et al. Does total disc arthroplasty in C3/C4-segments change the kinematic features of axial rotation? J Biomech 2013;46:1739-45.

41. Chang PY, Chang HK, Wu JC, et al. Differences be- 
tween C3-4 and other subaxial levels of cervical disc arthroplasty: more heterotopic ossification at the 5-year follow-up. J Neurosurg Spine 2016;24:752-9.

42. Yi S, Oh J, Choi G, et al. The fate of heterotopic ossification associated with cervical artificial disc replacement. Spine (Phila Pa 1976) 2014;39:2078-83.

43. Kong L, Ma Q, Meng F, Cao J, Yu K, Shen Y. The prevalence of heterotopic ossification among patients after cervical artificial disc replacement: a systematic review and meta-analysis. Medicine (Baltimore) 2017;96:e7163.

44. Hui N, Phan K, Kerferd J, Lee M, Mobbs RJ. Prevalence of and risk factors for heterotopic ossification after cervical total disc replacement: a systematic review and meta-analysis. Global Spine J 2020;10:790804.

45. Cardoso MJ, Rosner MK. Multilevel cervical arthroplasty with artificial disc replacement. Neurosurg Focus 2010;28:E19.

46. Pimenta L, McAfee PC, Cappuccino A, Bellera FP, Link HD. Clinical experience with the new artificial cervical PCM (Cervitech) disc. Spine J 2004;4(6 Suppl):315S-321S.

47. Amit A, Dorward N. Bryan cervical disc prosthesis: 12-month clinical outcome. Br J Neurosurg 2007;21:478-84.

48. Du J, Li M, Liu H, Meng H, He Q, Luo Z. Early follow-up outcomes after treatment of degenerative disc disease with the discover cervical disc prosthesis. Spine J 2011;11:281-9.

49. Cardoso MJ, Mendelsohn A, Rosner MK. Cervical hybrid arthroplasty with 2 unique fusion techniques. J Neurosurg Spine 2011;15:48-54.

50. Park JH, Roh KH, Cho JY, Ra YS, Rhim SC, Noh SW. Comparative analysis of cervical arthroplasty using mobi-c(r) and anterior cervical discectomy and fusion using the solis(r) -cage. J Korean Neurosurg Soc 2008;44:217-21.

51. Zarkadis NJ, Cleveland AW, Kusnezov NA, Dunn JC, Caram PM, Herzog JP. Outcomes following multilevel cervical disc arthroplasty in the young active population. Mil Med 2017;182:e1790-4.

52. Li J, Liang L, Ye XF, Qi M, Chen HJ, Yuan W. Cervical arthroplasty with Discover prosthesis: clinical outcomes and analysis of factors that may influence postoperative range of motion. Eur Spine J 2013;22:2303-9.
53. Wang Q, Cheng H, Mao Z, Qi X, Zhang M, Chen Y. Clinical and radiographic results after treatment of cervical degenerative disc disease with the bryan disc prosthesis: a prospective study with 2-year follow-up. Acta Orthop Belg 2011;77:809-15.

54. Cheng L, Nie L, Zhang L, Hou Y. Fusion versus Bryan cervical disc in two-level cervical disc disease: a prospective, randomised study. Int Orthop 2009;33:1347-51.

55. Reyes-Sanchez A, Miramontes V, Olivarez LM, Aquirre AA, Quiroz AO, Zarate-Kalfopulos B. Initial clinical experience with a next-generation artificial disc for the treatment of symptomatic degenerative cervical radiculopathy. SAS J 2010;4:9-15.

56. Yang YC, Nie L, Cheng L, Hou Y. Clinical and radiographic reports following cervical arthroplasty: a 24-month follow-up. Int Orthop 2009;33:1037-42.

57. Bhadra AK, Raman AS, Casey AT, Crawford RJ. Single-level cervical radiculopathy: clinical outcome and cost-effectiveness of four techniques of anterior cervical discectomy and fusion and disc arthroplasty. Eur Spine J 2009;18:232-7.

58. Wu TK, Wang BY, Cheng D, et al. Clinical and radiographic features of hybrid surgery for the treatment of skip-level cervical degenerative disc disease: a minimum 24-month follow-up. J Clin Neurosci 2017;40:102-8.

59. Wu T, Wang B, Ding C, et al. Artificial cervical disc replacement with the Prestige-LP prosthesis for the treatment of non-contiguous 2-level cervical degenerative disc disease: a minimum 24-month follow-up. Clin Neurol Neurosurg 2017;152:57-62.

60. Qizhi S, Lei S, Peijia L, et al. A comparison of zeroprofile devices and artificial cervical disks in patients with 2 noncontiguous levels of cervical spondylosis. Clin Spine Surg 2016;29:E61-6.

61. Ding F, Jia Z, Wu Y, Li C, He Q, Ruan D. Fusionnonfusion hybrid construct versus anterior cervical hybrid decompression and fusion: a comparative study for 3-level cervical degenerative disc diseases. Spine (Phila Pa 1976) 2014;39:1934-42.

62. Peng CW, Yue WM, Basit A, et al. Intermediate results of the prestige LP cervical disc replacement: clinical and radiological analysis with minimum twoyear follow-up. Spine (Phila Pa 1976) 2011;36:E10511.

63. Yi S, Kim KN, Yang MS, et al. Difference in occur- 
rence of heterotopic ossification according to prosthesis type in the cervical artificial disc replacement. Spine (Phila Pa 1976) 2010;35:1556-61.

64. Zhang Z, Zhu W, Zhu L, Du Y. Midterm outcomes of total cervical total disc replacement with Bryan prosthesis. Eur J Orthop Surg Traumatol 2014;24 Suppl 1:S275-81.

65. Kim SH, Chung YS, Ropper AE, et al. Bone loss of the superior adjacent vertebral body immediately posterior to the anterior flange of Bryan cervical disc. Eur Spine J 2015;24:2872-9.

66. Tian W, Yan K, Han X, Yu J, Jin P, Han X. Comparison of the clinical and radiographic results between cervical artificial disk replacement and anterior cervical fusion: a 6-year prospective nonrandomized comparative study. Clin Spine Surg 2017;30:E578-86.

67. Gao X, Yang Y, Liu H, et al. Cervical disc arthroplasty with Prestige-LP for the treatment of contiguous 2-level cervical degenerative disc disease: 5-year follow-up results. Medicine (Baltimore) 2018;97:e9671.

68. Turner I, Choi D. NuNec(TM) cervical disc arthroplasty improves quality of life in cervical radiculopathy and myelopathy: a 2-yr follow-up. Neurosurgery 2018;83:422-8.

69. Chen F, Yang J, Ni B, Guo Q, Lu X, Xie N. Clinical and radiological follow-up of single-level Prestige LP cervical disc replacement. Arch Orthop Trauma Surg 2013;133:473-80.

70. Fay LY, Huang WC, Tsai TY, et al. Differences between arthroplasty and anterior cervical fusion in two-level cervical degenerative disc disease. Eur Spine J 2014;23:627-34.

71. Miao J, Yu F, Shen Y, et al. Clinical and radiographic outcomes of cervical disc replacement with a new prosthesis. Spine J 2014;14:878-83.

72. Chang HK, Chang CC, Tu TH, et al. Can segmental mobility be increased by cervical arthroplasty? Neurosurg Focus 2017;42:E3.

73. Lee JH, Jung TG, Kim HS, Jang JS, Lee SH. Analysis of the incidence and clinical effect of the heterotopic ossification in a single-level cervical artificial disc replacement. Spine J 2010;10:676-82.

74. Cheng L, Nie L, Li M, Huo Y, Pan X. Superiority of the $\operatorname{Bryan}(\mathrm{R})$ disc prosthesis for cervical myelopathy: a randomized study with 3-year followup. Clin Orthop Relat Res 2011;469:3408-14.

75. Yang H, Lu X, Yuan W, Wang X, Chen D, Zhao D.
Artificial disk replacement in the treatment of degenerative cervical disk disorder: a 30-year follow-up study. Spine (Phila Pa 1976) 2014;39:1564-71.

76. Zhang HX, Shao YD, Chen Y, et al. A prospective, randomised, controlled multicentre study comparing cervical disc replacement with anterior cervical decompression and fusion. Int Orthop 2014;38:253341.

77. Lee SE, Jahng TA, Kim HJ. Correlation between cervical lordosis and adjacent segment pathology after anterior cervical spinal surgery. Eur Spine J 2015;24:2899-909.

78. Phillips FM, Geisler FH, Gilder KM, Reah C, Howell KM, McAfee PC. Long-term outcomes of the US FDA IDE prospective, randomized controlled clinical trial comparing PCM cervical disc arthroplasty with anterior cervical discectomy and fusion. Spine (Phila Pa 1976) 2015;40:674-83.

79. Shichang L, Yueming S, Limin L, et al. Clinical and radiologic comparison of dynamic cervical implant arthroplasty and cervical total disc replacement for single-level cervical degenerative disc disease. J Clin Neurosci 2016;27:102-9.

80. Bin S, Xiangwang H, Sheng X, et al. Artificial cervical disk replacement for the treatment of adjacent segment disease after anterior cervical decompression and fusion. Clin Spine Surg 2017;30:E587-91.

81. Radcliff KE, Davis RJ, Hoffman GA, et al. Sevenyear clinical results of cervical total disc replacement compared with anterior discectomy and fusion for treatment of two-level symptomatic degenerative disc disease: a prospective, randomized, controlled, multicenter FDA clinical trial. Spine J 2016;16:S204.

82. Walraevens J, Demaerel P, Suetens P, et al. Longitudinal prospective long-term radiographic follow-up after treatment of single-level cervical disk disease with the Bryan cervical disc. Neurosurgery 2010;67:67987.

83. Coric D, Guyer RD, Nunley PD, et al. Prospective, randomized multicenter study of cervical arthroplasty versus anterior cervical discectomy and fusion: 5 -year results with a metal-on-metal artificial disc. J Neurosurg Spine 2018;28:252-61.

84. Chen J, Wang X, Bai W, Shen X, Yuan W. Prevalence of heterotopic ossification after cervical total disc arthroplasty: a meta-analysis. Eur Spine J 2012;21:67480. 
85. Meisel HJ, Jurak L, Antinheimo J, et al. Four-year results of a prospective single-arm study on 200 semi-constrained total cervical disc prostheses: clini$\mathrm{cal}$ and radiographic outcome. J Neurosurg Spine 2016;25:556-65.

86. Zhao Y, Zhang Y, Sun Y, Pan S, Zhou F, Liu Z. Application of cervical arthroplasty with Bryan cervical disc: 10-year follow-up results in China. Spine (Phila Pa 1976) 2016;41:111-5.
87. Luo J, Gong M, Huang S, Yu T, Zou X. Incidence of adjacent segment degeneration in cervical disc arthroplasty versus anterior cervical decompression and fusion meta-analysis of prospective studies. Arch Orthop Trauma Surg 2015;135:155-60.

88. Zhou HH, Qu Y, Dong RP, Kang MY, Zhao JW. Does heterotopic ossification affect the outcomes of cervical total disc replacement?: a meta-analysis. Spine (Phila Pa 1976) 2015;40:E332-40. 